\title{
O que as crianças nos contam sobre a cidade? Interlocuções entre infâncias, educação infantil e cidades
}

\author{
What do children tell us about the city? Interlocutions between childhoods, early childhood \\ education and cities
}

¿Qué nos dicen los niños de la ciudad? Interlocuciones entre la infancia, la educación en la primera infancia y las ciudades

\author{
Victória Galter Vieira \\ ORCID: https://orcid.org/0000-0003-2475-1223 \\ Prefeitura Municipal de Vitória, Brasil \\ E-mail: victoria-galter@hotmail.com \\ Rennati Taquini \\ ORCID: https://orcid.org/0000-0001-9006-3053 \\ Prefeitura Municipal de Guarapari, Brasil \\ E-mail: rennati@gmail.com \\ Franceila Auer \\ ORCID: https://orcid.org/0000-0002-1913-854X \\ Prefeitura Municipal de Vitória, Brasil \\ E-mail: auerfranceila@gmail.com \\ Larissa Franco de Mello Aquino Pinheiro \\ ORCID: https://orcid.org/0000-0002-1568-6370 \\ Universidade Federal do Espírito Santo, Brasil \\ E-mail: larissafma @gmail.com \\ Vania Carvalho de Araújo \\ ORCID: https://orcid.org/0000-0002-7678-1689 \\ Universidade Federal do Espírito Santo, Brasil \\ E-mail: vcaraujoufes@gmail.com
}

\begin{abstract}
Resumo
Este artigo tem como objetivo analisar as experiências vivenciadas pelas crianças na cidade em que habitam, a partir de suas impressões. Adota o estudo exploratório como metodologia, tendo como instrumentos de pesquisa, entrevistas semiestruturadas, rodas de conversa, diário de campo, registros fotográficos, acompanhamento de passeios, bem como a observação das crianças em seus momentos de interações, brincadeiras e produção de desenhos. Trata-se de uma pesquisa realizada com dezessete crianças de cinco anos de idade matriculadas em um Centro de Educação Infantil localizado nas dependências da Universidade Federal do Espírito Santo, assumindo-as como copartícipes na produção dos dados. Os resultados indicam que, por meio de diferentes linguagens, as crianças representam a cidade de diversas formas, como o lugar onde as pessoas moram, trabalham, estudam, passeiam, convivem e brincam, tudo isso, em companhia de seus pares e de outras categorias geracionais. Além disso, ao discorrerem sobre os lugares que frequentam na cidade, elas reivindicam melhorias para os espaços públicos, sobretudo para os parques e as praças, sendo estes, pontos que podem ser convidativos para a coabitação e o encontro. Conclui-se que a construção de um espaço público compartilhado de convivência plural pressupõe pensarmos uma cidade que inclua as crianças e suas infâncias.
\end{abstract}

Palavras-chave: Infâncias; Cidades; Educação infantil e cidades.

\begin{abstract}
This paper aims to analyze the experiences lived by children in the city where they live, based on their impressions. It adopts the exploratory study as methodology, with semi-structured interviews, dialogue circles, field diary, photographic records and monitoring of tours as research instruments, as well as the observation of children in their moments of interactions, games and drawing production. This is a study carried out with seventeen children aged five years old enrolled in a Center for Early Childhood Education located at the Federal University of Espírito Santo, assuming them as co-participants in the production of data. The results indicate that, through different languages, children represent the city as the place where people live, work, study, walk around, socialize and play, in the company of their peers and other generational categories. Furthermore, when they talk about the places they frequent in the city, they claim improvements to public spaces, especially concerning parks and squares, and these are points
\end{abstract}


that can be inviting for the cohabitation and meeting. It is concluded that the construction of a shared public space of plural coexistence presupposes thinking of a city that includes children and their childhoods.

Keywords: Childhoods; Cities; Early childhood education and cities.

\section{Resumen}

Este artículo tiene como objetivo analizar las experiencias vividas por los niños en la ciudad en la que viven, a partir de sus impresiones. Adopta el estudio exploratorio como metodología, teniendo como instrumentos de investigación, entrevistas semiestructuradas, ruedas de conversación, diario de campo, registros fotográficos, seguimiento de recorridos, así como la observación de los niños en sus momentos de interacciones, juegos y producción de dibujos. Se trata de una investigación realizada con diecisiete niños de cinco años inscritos en un Centro de Educación Infantil ubicado en las instalaciones de la Universidad Federal de Espírito Santo, asumiendo como co-participantes en la producción de los datos. Los resultados indican que, a través de diferentes idiomas, los niños representan a la ciudad de diversas maneras, como el lugar donde viven las personas, trabajan, estudian, caminan, conviven y juegan, todo en compañía de sus compañeros y otras categorías generacionales. Además, al hablar de los lugares que frecuentan en la ciudad, exigen mejoras en los espacios públicos, especialmente para parques y plazas, siendo estos puntos los que pueden ser atractivos para la convivencia y la reunión. Se concluye que la construcción de un espacio público compartido de convivencia plural presupone pensar en una ciudad que incluya a los niños y sus infancias.

Palabras clave: Infancias; Ciudades; Educación y ciudades de la primera infancia.

\section{Introdução: Infâncias, Educação Infantil e Cidades}

O reconhecimento das crianças como atores sociais por meio de suas culturas infantis implica também "[...] pensar a cidade e a educação como espaços socioculturais em que os direitos se colocam no cotidiano [como pressupostos fundamentais] para uma cidade educadora" (Araújo, 2011, p. 14). Historicamente, a escola tem sido considerada uma instituição importante na formação educativa das crianças, locus privilegiado para produção e socialização do conhecimento e de práticas sociais. No entanto, se por um lado é reconhecida publicamente como o espaço mais adequado para a presença das crianças na cidade, por outro lado parece pospor outras experiências possíveis de acontecer extramuros escolares (Derbortoli, 2008), capazes de introduzir as crianças ao mundo e na memória da comunidade.

Uma análise suscinta dos documentos norteadores da educação nacional nos permite entrever a efemeridade - ou até mesmo inexistência - da cidade como possibilidade educativa nos modos de participação das crianças em suas tessituras sociais. Partindo da promulgação da Lei de Diretrizes e Bases da Educação Nacional (Lei n. 9.394, 1996), passando pela publicação das Diretrizes Curriculares Nacionais para a Educação Infantil (Resolução n. 5, 2009), até a aprovação do Plano Nacional de Educação (Lei n. 13.005, 2014) vigente, observamos que a palavra "cidade" sequer é mencionada nas referências voltadas à educação infantil, em detrimento de um conceito universal de comunidade, ora pela via simbólica do "[...] estabelecimento de uma relação afetiva com a comunidade local [...] e a consideração dos saberes da comunidade" (Resolução n. 5, 2009, p. 19), ora de forma mais institucionalizada, por meio da "[...] articulação da escola com os diferentes espaços educativos, culturais e esportivos e com equipamentos públicos, como centros comunitários, bibliotecas, praças, parques, museus, teatros, cinemas e planetários" (Lei n. 13.005, 2014, p. 4).

O verbete "cidade" aparece pela primeira vez, ainda que timidamente, na Base Nacional Curricular Comum (Resolução n. 2, 2017, p. 42) ao mencionar que as crianças desde pequenas buscam se situar "[...] em diversos espaços (rua, bairro, cidade etc.) [...] [e] demonstram também curiosidade sobre [...] o mundo sociocultural", contexto em que a cidade se revela como uma experiência possível na constituição de um arranjo curricular, ao acolher os saberes e as vivências cotidianas das crianças entrelaçados aos conhecimentos oriundos do patrimônio cultural.

A defesa pela afirmação da cidade nos documentos educacionais suscita pensar a cidade como um conjunto de experiências concretizadas em sociedade. Os artefatos culturais e sociais que se encontram historicamente disponíveis na sociedade podem qualificar as responsabilidades públicas que a escola tem na formação das crianças, pois certos desafios estão intimamente ligados às questões básicas da vida social de modo que "[...] quanto mais diversificado o meio sociocultural, maiores serão as possibilidades de conhecimento, de criação" (Müller \& Redin, 2007, p. 17) e de formação. 
As discussões acerca da escola e sua relação com a cidade ganham relevância, sobretudo, a partir de algumas iniciativas no âmbito das políticas públicas para tornar visível a cidade na escola e a escola na cidade. Como exemplo, podemos citar propostas em curso que procuram ampliar formas de participação das crianças na cidade, chamando a atenção para o reconhecimento das crianças e das suas culturas e da cidade como um espaço referente de possibilidades educativas. Dentre as propostas, destacamos duas que tem se constituído em uma ação de larga escala em diferentes países, como por exemplo, a Carta das Cidades Educadoras ao reafirmar o direito a uma cidade educadora "[...] como uma extensão do direito fundamental de todos os indivíduos à educação" (Cenpec, 2006, p. 158) e a Cidade Amiga das Crianças ao pressupor que sejam respeitados os direitos da criança a serviços essenciais, também por promover "[...] os direitos da criança andar sozinha nas ruas com segurança, encontrar amigos e brincar [...] participar de eventos culturais e sociais e exercer sua cidadania em condições de igualdade em sua cidade, com acesso a todos os serviços" (Fundo de Emergência Internacional das Nações Unidas para a Infância [UNICEF], 2009).

Não obstante as iniciativas de âmbito internacional, pesquisas no Brasil são difundidas com o intuito de chamar a atenção para o necessário reconhecimento dos direitos das crianças aos diferentes espaços e tempos da cidade e as possibilidades de uma maior articulação entre a cidade e a escola (Araújo, 2019; Müller, 2012). Tais iniciativas, sem dúvida, traduzem uma sensibilidade acerca das condições de vida das crianças e nos desafiam a promover políticas públicas e a refletir sobre os enunciados que vão se constituindo em torno de tais afirmativas, sobretudo se levarmos em conta que as mesmas crianças que se encontram matriculadas nas escolas, são as que convivem diariamente com os efeitos, muitas vezes, perversos e constrangedores da cidade. Quando se trata de crianças mais novas, essas questões tendem a se complexificar não apenas por requererem formas mais intensivas de proteção, mas por estarem desprovidas de visibilidade pública (Sarmento, 2007).

Embora os documentos supracitados e as pesquisas realizadas reiterem a cidade como um direito de todos, na contemporaneidade nem sempre percebemos uma prática social capaz de garantir efetivamente o usufruto desse direito, tendo em vista a manutenção de padrões de exclusão que reforçam a desigualdade social e reafirmam uma sociedade na qual muitos não têm sequer o seu direito de ir e vir assegurado, especialmente as crianças que "[...] são prejudicadas em função de sua relativa invisibilidade face às políticas públicas, de sua exclusão dos processos de decisão na vida coletiva [...]" (Dias \& Ferreira, 2015, p. 119). Mesmo com as limitações e mazelas sociais presentes no contexto urbano, as quais atingem sobretudo as crianças, a prática educadora se dá também nas relações entre os sujeitos de diferentes gerações e no contato que estabelecem com a cidade em que habitam pois,"“[...] nela, indivíduos se inter-relacionam com outros sujeitos sociais numa rede em que coexistem contextos e espaços múltiplos e diversificados que contribuem para a formação das identidades sociais e pessoais" (Dias \& Ferreira, 2015, p. 118).

Por meio de suas relacionalidades com pessoas de diferentes categorias geracionais e de contextos sociais variados, com as diversas experiências cotidianas e com os mais diversos espaços da cidade, as crianças recriam e ressignificam a sua realidade. Elas são caçadoras, buscando constantemente realizar novas descobertas, em diversos espaços, através de suas brincadeiras, as quais as possibilitam produzir cultura, imaginar, se desenvolver, recriar, reinventar, reinterpretar o mundo e produzir novos significados, saberes e práticas. De acordo com Kramer (2007), a cultura infantil é produção e criação, constituindo uma dinâmica em que as crianças produzem cultura e são produzidas na cultura que se inserem. Assim, a interpretação das culturas infantis "[...] não pode ser realizada no vazio social, e necessita de se sustentar na análise das condições sociais em que as crianças vivem, interagem e dão sentido ao que fazem" (Pinto \& Sarmento, 1997, p. 6). Por sua vez, Kramer (2007) destaca que as crianças não formam uma comunidade isolada, visto que elas são parte de um grupo e suas brincadeiras expressam esse pertencimento. 
Manoel de Barros (2015) em sua obra poética Meu quintal é maior que o mundo retrata as miudezas das infâncias e a diversidade cultural das crianças em seus modos de existência cotidiana e se autodenomina um "caçador de achadouros da infância":

Se a gente cavar um buraco ao pé da goiabeira do quintal, lá estará um guri ensaiando subir na goiabeira. Se a gente cavar um buraco ao pé do galinheiro, lá estará um guri tentando agarrar no rabo de uma lagartixa. Sou hoje um caçador de achadouros de infância. Vou meio dementado e enxada às costas a cavar no meu quintal vestígios dos meninos que fomos (Barros, 2015, p. 124).

Assim como Manoel de Barros (2015), em busca por encontrar as crianças em suas experiências nos diversos espaços potenciais de brincadeiras, pretendemos, neste artigo, analisar as experiências vivenciadas pelas crianças na cidade em que habitam, a partir de suas impressões. Na condição de "caçadoras de achadouros da infância" procuramos, a partir de memórias individuais e coletivas, capturar aquilo que tenha sido marcante nas vivências das crianças na cidade, a partir do que elas nos contam.

\section{Metodologia: a Pesquisa com Crianças}

A opção metodológica pelo estudo exploratório, de acordo com Gil (2002), viabiliza diferentes possibilidades investigativas sobre o assunto em estudo, traduzidas pelos modos como as crianças se apropriam do território onde vivem e mobilizam outras formas de pensar. Assim, formas reflexivas e críticas são decorrentes da aproximação com a realidade investigada, que foram se tornando visíveis no decorrer do próprio processo de pesquisa e na interlocução com os sujeitos e suas realidades de vida.

A investigação desenvolve-se durante três meses em um Centro de Educação Infantil - CEI localizado nas dependências da Universidade Federal do Espírito Santo - Ufes. Há que se destacar que a escolha pela turma ocorreu tendo em vista a proposta pedagógica em andamento desenvolvida pela professora regente Élida, ${ }^{1}$ sobre as crianças e infâncias na cidade. A ética na pesquisa com crianças exige-nos uma atenção especial, e, após explicação sobre o motivo do encontro e do objetivo da pesquisa, a pergunta sobre quem gostaria de participar resulta no assentimento de 17 crianças (9 meninas e 8 meninos) de cinco anos de idade, que levantam suas mãos como gesto de concordância ao convite, de modo que o aceite decorre do desejo pessoal de cada uma delas, sem forjar qualquer situação artificial que pudesse induzi-las à tomada de decisão, reiterando, inclusive, a possibilidade de desistência a qualquer momento, caso desejassem. Fernandes (2009, p. 127) destaca outro aspecto importante no processo de pesquisa com crianças.

[...] se é inegável que os adultos possuem, em geral, conhecimentos mais alargados do que a maior parte das crianças, decorrentes de seu percurso de vida, também é inegável que quem melhor sabe o significado de ser criança, de pertencer ao grupo social das crianças, são as crianças, logo são elas que nesta área possuem um conhecimento mais alargado acerca do conjunto de aspectos que lhe conferem identidade. Pensar em processos de investigação com crianças que sejam informados eticamente implica, então, valorizar as competências destas na interpretação da realidade social e valorizar, ainda, as interacções negociadas e abertas entre adultos e crianças.

Afinal, quem melhor do que as próprias crianças poderia falar sobre o que viveram - ou ainda vivem - na cidade? Para capturar as sutilezas de suas impressões, constituem os instrumentos de pesquisa, diário de campo, registros fotográficos, entrevistas semiestruturadas, rodas de conversa, acompanhamento de passeios, bem como a observação das crianças em seus momentos de interações, brincadeiras e produção de desenhos. Lançar mão de uma certa variedade de instrumentos de coleta e produção de dados na inter-relação com as crianças é justificada levando em consideração que em um processo de pesquisa

\footnotetext{
${ }^{1}$ Todos os nomes mencionados na análise da pesquisa são fictícios, escolhidos pelas crianças.
} 
quando o outro é uma criança "[...] a linguagem oral não é central nem única, mas fortemente acompanhada de outras expressões corporais, gestuais e faciais" (Rocha, 2008, p. 45).

Compreender as relações que se estabelecem entre a escola, a cidade, as crianças e suas infâncias nos ajuda a perceber as filigranas de uma experiência pouco visível ao conjunto da sociedade. Ao privilegiar uma relação dialógica entre o pesquisador, a pesquisa com crianças nos exige uma percepção mais sensível da realidade a ser investigada, ao passo em que nos ajuda a transgredir fronteiras simbólicas e sociais entre a cidade, a escola e suas diferentes infâncias ainda não perceptíveis e muitas vezes, percebidas como irrelevantes.

\section{Resultados e Discussão: a Experiência na Cidade a Partir das Crianças}

A entrada inicial em campo já nos revela que, por mais que as crianças tenham que acordar cedo para irem para ao CEI, cujo horário de entrada é às sete horas da manhã, elas chegam à instituição animadas para irem às suas respectivas salas e se encontrarem com seus colegas e professoras. Observamos também que as crianças chegam acompanhadas de seus pais, tios ou responsáveis, de carro, de vans, de bicicleta, de ônibus ou a pé.

Desde o primeiro momento, buscamos nos aproximar das crianças, a fim de conquistar a confiança delas. De acordo com Silva, Barbosa e Kramer (2005, p. 43) "[...] é condição para o pesquisador das ciências humanas reconhecer seus próprios limites, explicitar o ponto de vista de onde realiza a investigação, se inquietar, indagar", o que justifica nossa preocupação em criar vínculos com as crianças e realizar uma escuta sensível. Brincar com as crianças e participar dos momentos de roda, respondendo a uma demanda apresentada por elas, contribuiu para estreitar nossos laços de intimidade.

Uma das experiências em nossa pesquisa com as crianças diz respeito ao acompanhamento de seus passeios. Durante o percurso feito de ônibus até uma galeria de arte, cantamos várias músicas. Em alguns momentos, Beatriz, Alice e Débora conversam sobre o que veem no caminho. Quando passamos pela Fábrica de Ideias, ${ }^{2}$ Alice diz: "Olha! No muro desse lugar tem um monte de pintura, igual no lugar que a gente tá indo!". Já próximo a Curva do Saldanha, ${ }^{3} \mathrm{em}$ frente à Baía de Vitória, Débora grita: "Olha gente, o mar! Tem um monte de barco lá! E Beatriz acrescenta: "Não é barco, é navio, né?" Luiza continua: "Nossa, como é lindo o mar!” (DIÁRIO DE CAMPO).

As crianças ao percorrem as ruas das cidades, enxergam através da janela do ônibus várias cenas do cotidiano. Em diálogo com Gadotti (2006) consideramos que a cidade, além de cumprir suas funções tradicionais (econômica, social, política e de prestação de serviços), exerce também outra função cuja finalidade é a formação para e pela cidade, portanto, uma função educativa. Ele propõe uma pedagogia da cidade "[...] para nos ensinar a olhar, a descobrir a cidade, para poder aprender com ela, dela, aprender a conviver com ela" (Gadotti, 2006, p. 05).

Em outro momento da pesquisa, assistimos ao trailer do documentário Territórios do Brincar e as crianças prestam muita atenção, ficam empolgadas e pedem para assistirmos novamente. Em seguida, perguntamos para as crianças o que elas mais gostam do vídeo:

\section{Neymar: Eu gosto de brincar de amarelinha!}

Derick: Eu também já fiz piscina de areia na praia.

Alice: Nossa, tem um monte de brincadeira legal, né?

\footnotetext{
${ }^{2}$ É o local da antiga Fábrica 747 (fábrica de juta/têxtil), no bairro de Jucutuquara, onde hoje se oferece estrutura física para o desenvolvimento de projetos e eventos abertos ao público.

${ }^{3}$ É uma parte da via pública no Centro da Cidade de onde se tem uma vista ampla da baía de Vitória, com destaque para o Morro do Penedo e do Porto de Vitória.
} 
Pesquisadora: Sim, muitas brincadeiras diferentes e muito legais, vocês viram? Agora vou passar outro vídeo que mostra crianças que moram em dois lugares diferentes conversando sobre o que tem no lugar onde elas moram e sobre quais as brincadeiras elas fazem. Eles conversam por meio de uma brincadeira. Vamos ver se vocês sabem qual é (Diário de Campo).

Em seguida, transmitimos o vídeo Disque Quilombola, que mostra crianças de uma comunidade quilombola do Espírito Santo confeccionando um brinquedo e depois conversando com crianças que moram no morro de São Benedito, em Vitória, por meio da brincadeira "telefone sem fio". Uma parte do "telefone", o qual foi feito de lata de leite em pó, ficou na comunidade quilombola e a outra parte foi levada de carro para o morro e os dois foram ligados por um enorme barbante. Logo após o início do vídeo Neymar já identifica a brincadeira.

\section{Neymar: É Telefone sem fio!}

Catarina: Vamos fazer essa brincadeira aqui também?

Pesquisadora: Podemos fazer sim! Vou conversar com a professora para conseguirmos as latas e a gente faz. Vocês viram que as próprias crianças fazem seus brinquedos? Elas fizeram o telefone sem fio, os carrinhos e vários outros. Também, as crianças do morro fazem brincadeiras diferentes das crianças do quilombo, porém todas elas fazem seus próprios brinquedos e inventam várias brincadeiras. Então crianças, foi muito legal a nossa conversa. Durante o tempo que passarei com vocês, iremos conversar muito sobre a cidade (Diário de Campo).

A professora Élida envia o bilhete aos pais para as crianças trazerem as latas de leite em pó. Quando conseguimos um grande número de latas, confeccionamos os telefones sem fio para realizarmos a brincadeira. No momento da roda de conversa, a professora explica que nos organizaríamos em duplas no pátio e cada uma pergunta por meio do telefone para o colega o que tem numa cidade?

Alice: Débora, o que tem numa cidade?

Débora: Tem bichos, tem vaca, carros.

Neymar: Lucas, o que tem na cidade?

Lucas: Numa cidade de verdade tem pessoas, polícia, ladrão, árvores.

Luiza: Maria Luiza, o que tem na cidade?

Maria Luiza: Um monte de casa, também tem as pessoas.

Denis: Olha gente, um macacooooooo.

Todas as crianças saíram correndo da roda pra ver o macaco que apareceu no pátio. Percebemos que, como elas dispersaram, era o momento de separar os telefones em dois e deixarem as crianças brincarem livremente.

Beatriz veio até a mim e disse:

Beatriz: Quero brincar de telefone com você.

Pesquisadora: Vamos brincar então. Beatriz, o que tem na cidade?

Beatriz: Vaca, cavalo, carro e moto.

Beatriz: Agora eu vou lá brincar com a Débora (Diário de Campo). 
Segundo Borba (2007), o brincar, ao promover uma articulação entre a realidade e fantasia, a experiência e a imaginação, permite que a criança vivencie outros papéis e assim reflita sobre suas relações com estes, tomando consciência de si e do mundo, criando outras realidades e lógicas. Ainda de acordo com Borba (2007, p. 41), "para que se abram e se ampliem as possibilidades de criação no brincar é imprescindível, contudo, que as crianças tenham acesso a espaços coletivos de brincadeira e a experiências de cultura".

Essas vivências na brincadeira "Telefone sem fio" despertam um maior interesse de Maria Luíza sobre a cidade, pois ela escolhe o livro "Minhas primeiras palavras: na cidade" e diz: Olha, eu achei uma história que fala sobre a cidade igual o seu trabalho, conta pra mim? (Diário de Campo). Logo, outras crianças se juntam a nós, todas sentadas no tapete da sala de aula do CEI, conforme a Figura 1 abaixo.

Figura 1 - Crianças observando as cenas do livro.

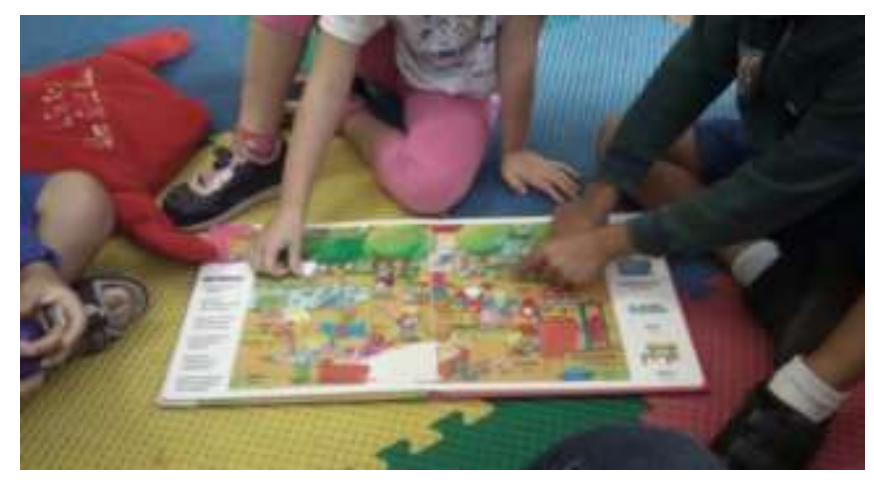

Fonte: Arquivo de campo.

Diante de tal situação, identificamos a partir da atitude de Maria Luiza, que as crianças conseguiam perceber que estávamos fazendo uma pesquisa com elas. Além disso, elas se mostram interessadas pelo tema "cidade" e em contribuir com o estudo. De acordo com Carvalho e Müller (2010), enquanto sujeitos copartícipes dos dados, as crianças são produtoras de história e contribuem para a transformação do mundo em que vivem com seus saberes.

Passados dias, visitamos a feira literária ambulante no estacionamento do Centro de Ciências Exatas da Ufes. Nesse dia acontece uma apresentação do Projeto Alman'arte, cujos autores contam a história de um livro e expõem um CD contendo poesias, textos literários e músicas. No caminho até a feira, ao passarmos perto de uma grande pedra Luiza diz: "Olha! Uma caverna! Tem até uma porta secreta. Derick complementa: Vamos andar rápido, porque senão os homens da caverna vão vir atrás de nós!" (DIÁRIO DE CAMPO). Chama-nos atenção o fato delas se encantarem com os próprios detalhes e sutilezas dos trajetos, como por exemplo a "caverna" (Figura 2) e não apenas chegarem ao destino do passeio, mostrando que a caminhada pode ser ainda mais interessante do que a chegada, pois toda essa travessia revela descobertas. 


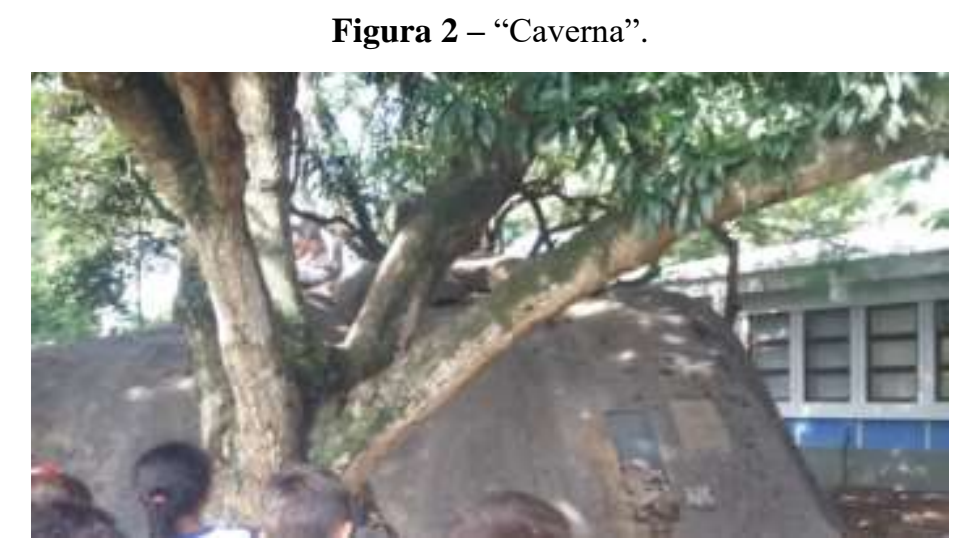

Fonte: Arquivo de campo.

Ao final do trajeto, nas proximidades da passarela da Ufes, Artuc afirma: "Aqui é onde meu pai estuda, eu já vim aqui um monte de vezes com ele!" Maria Luiza continua: "Maria Luiza: A minha mãe também estuda aqui”. Em seguida Catarina diz: "Meu pai trabalha aqui" (DIÁRIO DE CAMPO). Diante do exposto, percebemos que algumas crianças, que circulam pela Ufes com seus pais, identificam os prédios administrativos e de estudos dos adultos como um espaço diferente do CEI, onde estudam.

Chegamos à feira literária e sentamos com as crianças bem em frente ao palco. As crianças ficaram encantadas com a apresentação e pediram para eles cantarem a música "João Bananeira" que elas gostam muito. Quando o "João Bananeira" apareceu no palco elas ficaram muito eufóricas e cantaram alegremente a música do João Bananeira: "João bananeira chegou, com o canto da passarada, revoada nas sete voltas, alegria da criançada. Acorda, o dia brilha, o sol é luz que clareia a vida [...]” (Diário de Campo).

De acordo com Kramer (2007), o trabalho pedagógico tem como essência favorecer a experiência com a cultura, a qual está presente na literatura, na música, na dança, no teatro. Ainda para Kramer (2007, p. 19), "essa visão do pedagógico ajuda a pensar sobre a creche e a escola e a escola em suas dimensões políticas, éticas e estéticas. A educação, uma prática social, inclui o conhecimento científico, a arte e a vida cotidiana".

Freire (1993, p. 16) coloca a educação "[...] enquanto processo permanente e a vida das cidades, enquanto contextos que não apenas acolhem a prática educativa, como prática social, mas também constituem, através de suas múltiplas atividades, em contextos educativos em si mesmas". A partir desse ponto de vista é possível promover educação em qualquer espaço da cidade. Dessa forma, "[...] o educador deve contemplar a cidade, pensar a cidade, extrair de cada espaço dela as lições que possam dar mais vida às pessoas, humanizar os cidadãos”, como colocado por Chisté e Sgarbi (2016, p. 11).

Cabe aqui destacar uma atividade desenvolvida pela professora Élida que oportunizou a exposição das diferentes opiniões das crianças. Trata-se de uma votação entre as crianças a partir de suas próprias sugestões para definir o nome do "pátio de fundos" do CEI. Para tanto, são apresentadas imagens (Figura 3) do Parque da Cidade, ${ }^{4}$ Parque da Pedra da Cebola ${ }^{5}$ e

\footnotetext{
${ }^{4}$ Parque urbano que possui $115.180 \mathrm{~m}^{2}$, localizado na cidade de Serra. Conta com os seguintes equipamentos existentes: quadras poliesportivas; quadra de tênis; campo de futebol society; pista de skate; playground; ciclovia; pista de caminhada; bromeliário; estacionamento; auditório e Centro de Educação Ambiental.

${ }^{5}$ Parque urbano que possui $100.005 \mathrm{~m}^{2}$, localizado na cidade de Vitória, e, conta com uma vegetação típica de restinga. A origem do nome vem de uma pedra desenhada pela natureza no formato de uma grande cebola. Apresenta uma boa estrutura para atender o público, há uma casa de meditação e um jardim oriental, além de um mirante sobre uma grande parede rochosa, usada pelos adeptos do alpinismo. É possível visitar também o espaço cultural, com programações diversas no decorrer do ano. Apresenta uma grande área plana que sedia eventos, também utilizada para a prática de beisebol e futebol.
} 
Parque Botânico da Vale, ${ }^{6}$ os quais são frequentados por muitas das crianças das turmas, para mostrar que os parques têm nomes.

Figura 3 - Imagens de parques da Grande Vitória.

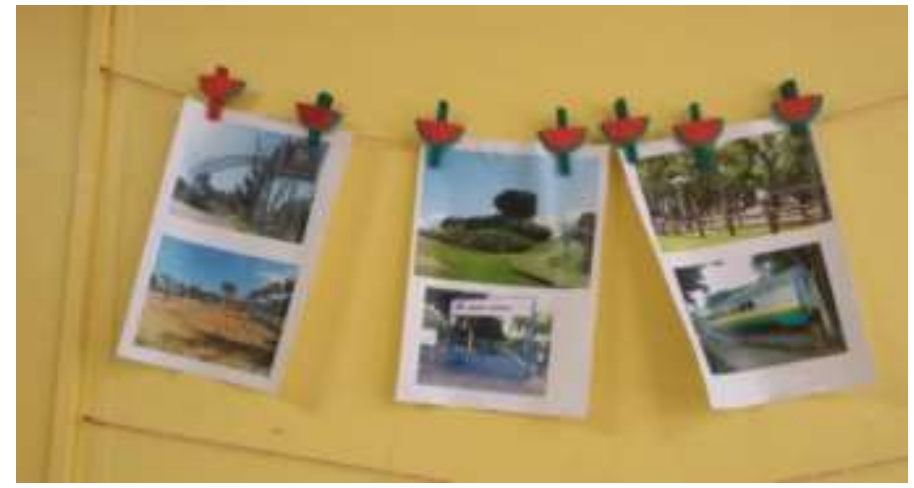

Fonte: Arquivo de campo.

Catarina: Eu quero que o nome seja "Pátio dos sonhos", porque no pátio a gente pode imaginar o que a gente quiser.

Derick: Eu escolho "Pátio faz-de-conta", porque no pátio a gente pode fazer de conta que é um monte de coisa: super-herói, cachorro...

Davi Luca: "Pátio do portal", porque o portal pode nos transportar para todas as brincadeiras.

Artuc: "Pátio das brincadeiras", porque a gente pode brincar de tudo lá (Diário de Campo).

Uma vez expostas as sugestões de todas as crianças, a maioria delas opta pelo nome "Pátio do portal". As crianças demonstram apreço pelo momento de votação, porque discutiram em conjunto sobre um assunto e com base nisso, fizeram uma escolha. De acordo com Sarmento, Fernandes e Tomás (2007, p. 197) “[...] a decisão das crianças sobre aspectos que dizem respeito às opções que se colocam no quotidiano escolar possui uma iniludível dimensão política e põe em relevo a necessidade que as crianças têm de dirimir entre valores e opções distintas".

Diante dos momentos de observação nas atividades realizadas no CEI e nos passeios, a pesquisa nos mostra que as diferentes experiências dentro e fora do contexto escolar potencializam o desenvolvimento das crianças. Para Loureiro (2010), as crianças permanecem grande parte de seu dia na escola e, por isso, torna-se desejável que a instituição possibilite às crianças experiências que contribuam para a sua formação humana. Depois de um mês em campo, quando conquistada a confiança e criado o vínculo de intimidade com as crianças, realizamos entrevistas semiestruturadas com elas, visando escutar suas histórias e percepções, entender com ainda mais profundidade o que elas têm a nos dizer sobre a cidade.

$\mathrm{Na}$ roda de conversa realizada no dia anterior ao início das entrevistas, conversamos com as crianças sobre o interesse de entrevistá-las, por meio de questões referentes às suas vivências na cidade, em seguida, perguntamos se todos sentiam desejo de participar.

Débora: Por que você vai entrevistar a gente?

\footnotetext{
${ }^{6}$ Parque particular pertencente ao Cinturão Verde da Vale, localizado na cidade de Vitória. É um espaço de lazer e vivência com a natureza, onde são desenvolvidas a partir de um Programa de Educação Ambiental, o que proporciona aos visitantes uma experiência educativa.
} 
Pesquisadora: Porque eu preciso da ajuda de vocês, para saber o que vocês pensam sobre a cidade. Vou fazer algumas perguntas e o que vocês responderem eu vou escrever no meu trabalho, vocês me ajudam?

Neymar: Sim, é muito legal ser entrevistado (Diário de Campo).

Como no primeiro dia o tempo não foi suficiente para entrevistar as 17 crianças da turma, prosseguimos na semana seguinte. Contudo, as crianças que não tinham sido chamadas inicialmente questionaram, dizendo que também gostariam de ser entrevistadas. Há que se destacar que as crianças foram participativas ao responder às perguntas e nos contar seus pensamentos e histórias. Procuramos ouvi-las de forma espontânea, deixando-as falar, sem nos prendermos somente às questões elaboradas previamente para as entrevistas. A respeito disso, Lopes (2018, p. 70) nos faz refletir sobre a potência que existe em "[...] compreender as crianças nos espaços vividos, buscando suas lógicas, ouvindo-as, aprendendo com elas, sentindo suas presenças no mundo, levando em conta suas contribuições, respeitando suas formas de ser e estar no espaço e no tempo atual".

Ao serem indagadas sobre quais são os lugares que mais gostam de ir na cidade, a maioria das crianças escolhe $o$ shopping. Tal fato demonstra que o shopping pode se configurar como um lugar estratégico para os pais levarem seus filhos para passear, tendo em vista que possui vários atrativos, como espaços para brincar, lanchar, ir ao cinema, além de ser um local considerado seguro. Em seguida aparece a escola, o que demonstra que as diversas atividades promovidas pelo CEI a tornam o lugar preferido para algumas delas; outras se referem a parques, bem como à casa de amigos e parentes e à própria casa.

Quando questionadas sobre quais são os lugares que menos gostam de ir na cidade, grande parte das crianças faz críticas à alguns espaços da cidade onde vivem e de outras cidades também:

Débora: Eu não gosto de ir na Pedra da Cebola, porque eu não gosto de brincar lá. Eu quero que muda os brinquedos, tem muitos brinquedos velhos lá.

Cristiano Ronaldo: Não gosto da escola que eu ia antes, porque lá não tinha quase nenhum brinquedo.

Olavo: No hotel de Guarapari, porque lá que não tinha nada pra criança.

Lucas: Não gosto de ir no restaurante, porque o meu pai e minha mãe vão num restaurante que não tem brinquedo, é só de almoçar.

Artuc: Sabe, eu não gosto de ir no cinema, porque não dá pra jogar lá (Diário de Campo).

Diante da fala das crianças, entendemos a necessidade de elas serem ouvidas sobre o que gostariam que tivesse nos lugares que são voltados para elas, como parques públicos e escolas, os quais foram citados por Débora e Cristiano Ronaldo. Bem sabemos que o Parque da Pedra da Cebola tem brinquedos em estado precário, o que pode fazer com que as crianças se machuquem e, por isso, algumas delas afirmam não gostar de brincar nesse espaço, manifestando desejos por brinquedos novos. De acordo com Dias e Ferreira (2015), embora as crianças representem uma parte significativa da sociedade e necessitem que a cidade contribua para seu desenvolvimento e para o exercício de sua cidadania, elas não participam dos processos de mobilização social. Diante disso, cabe aqui reiterar a relevância das crianças serem ouvidas no planejamento urbano.

Quando perguntadas sobre quais são os lugares da cidade que elas podem ir, a maioria das crianças responde que pode ir a parques, como o Parque da Pedra da Cebola, o Parque da Vale e o Parque da Cidade, "espaços produzidos por adultos para o uso infantil" (Lansky, Gouvea \& Gomes, 2014, p. 721); outras se referem a escola; ao shopping e à rua.

Artuc: Pode ir em qualquer rua, mas só quando não tem carro passando. Minha mãe me leva na rua pra comprar picolé. 
Débora: Pode andar de bicicleta e brincar na rua, porque a minha mãe deixa. Ela fica lá sentada me olhando (Diário de Campo).

Com a fala dessas duas crianças, é perceptível que elas gostam de brincar e circular pelas ruas, ainda que acompanhadas e vigiadas pelos pais, elas são possibilitadas por eles de frequentarem a rua, o que as permite estabelecerem diferentes sociabilidades e explorarem diferentes espaços. Segundo Gomes e Gouvea (2008, p. 56), “a rua, além de permitir o exercício da sociabilidade no interior dos grupos de pares, possibilita também uma outra construção/exploração do espaço" (Gomes \& Gouvea, 2008, p. 56).

Quando perguntadas sobre quais são os lugares da cidade que elas não podem ir, o trabalho dos pais; a montanharussa e espaços que tem animais perigosos são as respostas mais recorrentes dadas pelas crianças. Além disso, as crianças apontam o cinema de adultos; o hospital para visitar os doentes; ir à rua ou ao parquinho sozinhas. Embora seja comumente a percepção da rua como um lugar de perigo e de proibição às crianças, observamos que apenas uma delas cita a rua como um lugar que as crianças não podem frequentar.

Ao solicitarmos que contassem um acontecimento feliz que ocorreu no lugar onde vivem, das 17 crianças entrevistadas, mais de metade cita brincadeiras com primos, irmãos e amigos, seguido de comemorações de aniversário, recebimento de presentes e idas a parques de diversões. Quando pedimos que elas contassem um acontecimento triste que ocorreu no lugar onde vivem, poucas respondem que não aconteceu nada triste. Entretanto, a maioria relata situações que envolvem familiares e amigos, por exemplo, episódios de brigas com irmãos e amigos; morte de familiares, bem como o fato de irmãos teriam ido embora de casa.

\section{Cristiano Ronaldo: Quando eu tava na casa do meu pai e ninguém brincou comigo.}

Pesquisadora: Ninguém quem?

Cristiano Ronaldo: As crianças que ficam lá (Diário de Campo).

No momento de sua fala, Cristiano Ronaldo fica triste, demonstrando que esse acontecimento o marcou significativamente. Para a criança, as interações são importantes e quando ignoradas, de alguma forma, ficam ressentidas. A colocação de Luiza também nos chama a atenção. Luiza: "Eu só tenho que ficar na minha casa vendo vídeo, é chato" (DIÁRIO DE CAMPO). Essa fala expressa que ela sente falta de ocupar o seu tempo com outras programações que ultrapassem ficar apenas em casa em frente de uma tela midiática. Para Araújo (1996), a criança que no medievo mantinha mais vínculo com a rua, com as relações culturais e com as práticas sociais do universo adulto, a partir da nova organização sociocultural advinda na modernidade, passa a ser educada no interior da família, vivendo uma espécie de confinamento.

Quando questionadas sobre os quais lugares que elas passam em seu trajeto de casa até a escola, a maioria das crianças responde que perpassa a rua, os carros, as casas e os prédios. Por sua vez, as crianças da turma que moram em outros municípios relatam que passam por uma grande ponte (provavelmente em menção à Terceira Ponte), ${ }^{7}$ além de observarem outras paisagens:

Yasmin: Passo pela ponte e pelo mar.

Derick: Eu passo pela ponte e pelas ruas.

\footnotetext{
${ }^{7}$ A Terceira Ponte, oficialmente Ponte Deputado Darcy Castello de Mendonça, liga as cidades de Vitória e Vila Velha, no Espírito Santo. Foi a maior obra já realizada no estado e uma das maiores do Brasil, com 3,33km de extensão. O apelido Terceira Ponte veio logo que foi anunciado o projeto de sua construção, devido às duas outras pontes que já existiam anteriormente ligando Vitória a Vila Velha: Ponte Florentino Avidos (conhecida como Cinco Pontes) e Segunda Ponte (Ponte do Príncipe).
} 
Luiza: Pela ponte e por outro lugar que eu não sei o nome.

Artuc: Primeiro eu entro no carro, aí passo pela ponte, vejo a Praia da Costa e os navios, que são muito bonitos (Diário de Campo).

Araújo et al. (2018, p. 218) complementa a discussão ao afirmar que "as crianças imaginam a cidade a partir das suas experiências concretas de vida e das expectativas que criam por meio de diferentes dispositivos, sejam eles reais, sejam imaginários". Para além das entrevistas, também solicitamos que as crianças desenhassem o trajeto de suas casas até o CEI. Observamos que os desenhos dialogam diretamente com o que elas mencionam em suas falas (Figura 4).

Figura 4 - Trajeto de Artuc de casa até a escola.

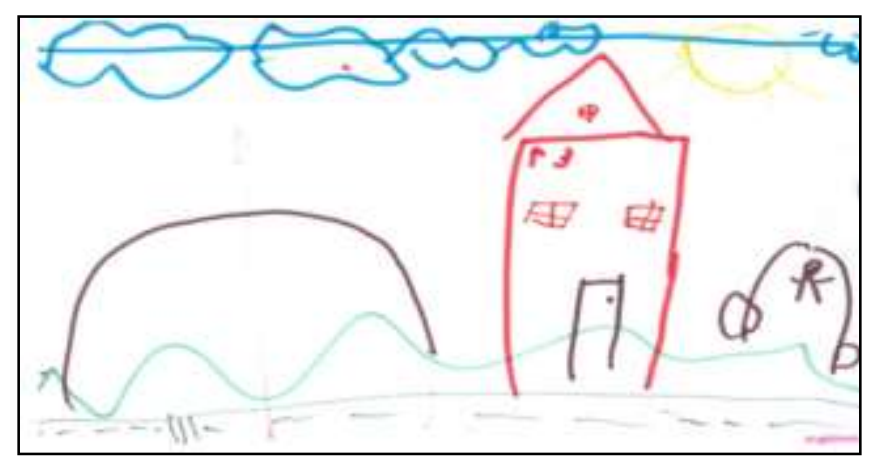

Fonte: Desenho produzido por Artuc, 5 anos. Arquivo de campo.

Olavo: Na Ponte da Passagem.

Catarina: Eu passo pela ponte da passagem, ando reto, passo pela casa com piscina e chego aqui.

Beatriz: Passo pela praia, pela ponte da passagem, depois passa embaixo do túnel e vem pra cá (Diário de Campo).

Diante disso, percebemos que as crianças são minuciosas em suas observações e identificam alguns dos pontos turísticos pelos quais elas passam em seu trajeto até a escola. Segundo Algebaile (1996, p. 123), ao ouvir as crianças, é importante que o pesquisador tenha sensibilidade, pois "perceber o todo que está por detrás das vozes individuais é um grande desafio, posto que exige do ouvinte/orquestrador profunda sensibilidade e uma atitude destituída de poder, permitindo as vozes se expressarem com propriedade". Também solicitamos que as crianças produzissem um desenho ilustrando a cidade em que vivem (Figuras 5 e 6 ).

Pesquisadora: Crianças, eu fiz uma entrevista com vocês né? Vocês lembram sobre o que eu perguntei?

Catarina: Várias coisas sobre a cidade.

Pesquisadora: Isso mesmo. Hoje eu vou pedir para vocês fazerem um desenho da cidade em que vocês moram.

Cristiano Ronaldo: Eu moro em duas cidades, posso fazer dois desenhos?

Pesquisadora: Pode sim.

Olavo: Eu também.

Pesquisadora: Eu dou duas folhas pra vocês dois (Diário de Campo). 
Figura 5 - Cidade onde a mãe de Cristiano Ronaldo mora.

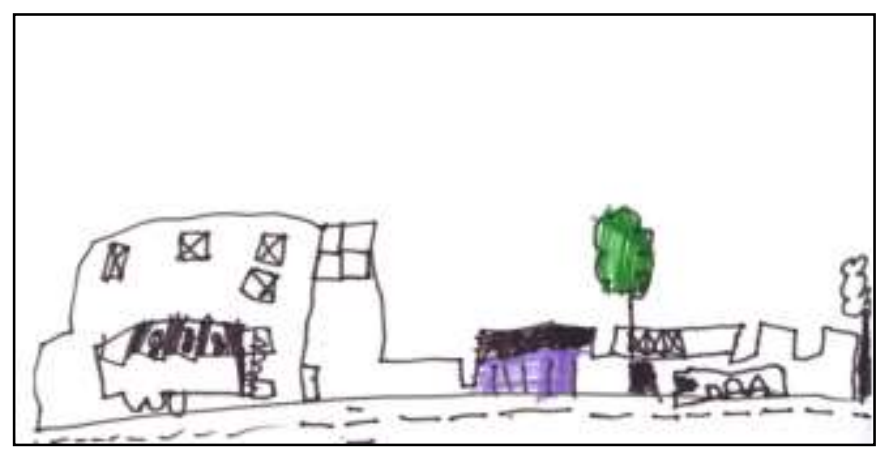

Fonte: Desenho produzido por Cristiano Ronaldo, 5 anos. Arquivo de campo.

Figura 6 - Cidade onde o pai de Cristiano Ronaldo mora.

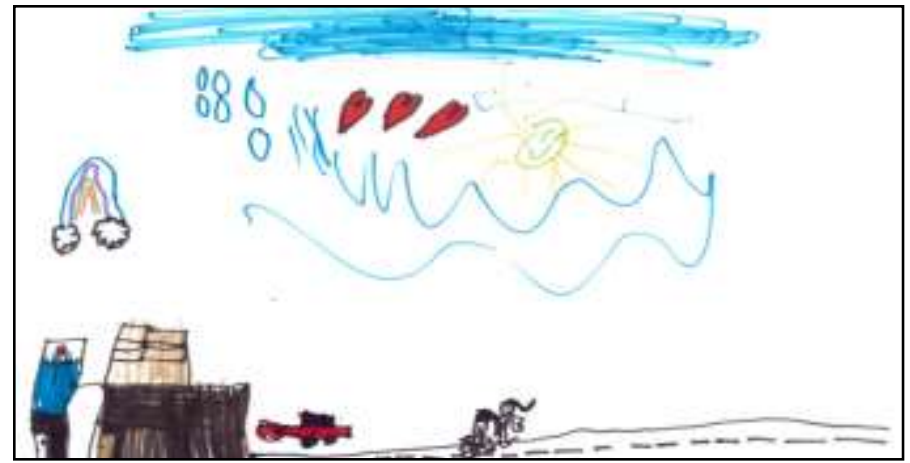

Fonte: Desenho produzido por Cristiano Ronaldo, 5 anos. Arquivo de campo.

Considerando que Cristiano Ronaldo mora em duas cidades, ele pede para fazer dois desenhos. A respeito deles afirma: "O primeiro desenho é a cidade que fica a casa da minha mãe. A casa da minha mãe é um prédio e fica mais longe da escola. O segundo desenho é a cidade do meu pai. O prédio do meu pai é mais perto da escola e tem piscina” (Diário de Сатро). Segundo Loureiro (2010), o desenho infantil não reproduz tudo o que a criança conhece sobre a cidade. Ele reproduz um instante, um fragmento, que são reveladores do que as crianças pensam, expostos em uma linguagem diferente da fala. Gobbi (2009, p. 80) ressalta que os desenhos conjugados à oralidade, veiculam "[...] informações sobre como esses meninos e meninas estão concebendo o contexto histórico e social no qual estão inseridos".

No último dia em campo, durante a roda de conversa, foi solicitado à professora Élida um momento com as crianças para o agradecimento à contribuição com a pesquisa e para a despedida, com um abraço em cada uma delas.

Pesquisadora: Então crianças, eu gostaria de agradecer muito a todos vocês! Vocês me ajudaram muito no desenvolvimento do trabalho. Vocês lembram algumas coisas que a gente fez durante o tempo em que eu estive aqui?

Neymar: Entrevista, desenho, telefone sem fio, um monte de coisa.

Pesquisadora: Isso mesmo, Neymar. Agora que já fizemos todas essas coisas e eu observei vocês brincarem e conversarem, eu vou ter que começar a escrever o trabalho. Por isso, hoje vai ser o último dia com vocês.

Davi Luca: Poxa, continua vindo aqui!

Pesquisadora: Pode deixar que virei visitar vocês! Mas hoje encerro a pesquisa.

Débora: Vou sentir saudades!

Pesquisadora: Eu também! Vou sentir saudade de todos vocês (Diário de Campo). 


\section{Considerações Finais}

A realização de uma pesquisa que reconhece as crianças como participantes ativas dos diferentes espaços da cidade “[...] implica considerá-las como categoria geracional e populacional importante num mundo que ainda se apresenta hostil às suas capacidades expressivas e de interpretação" (Araújo et al., 2018, p. 222). Ao colocarmos em evidência as impressões das crianças sobre suas experiências na cidade, fomos surpreendidas por uma série de discursos que revelam os modos próprios delas de ser e estar no mundo, o que muitas vezes se encontra aquém das marcas da cultura dos adultos.

Não obstante ao fato de a cultura dos adultos influenciar as formas de simbolização e de representação das crianças sobre o mundo, não podemos perder de vista que elas ainda assim ressignificam a sua realidade, enquanto atores sociais. Para Kramer (2007, p. 17), as crianças "[...] nascem no interior de uma classe, de uma etnia, de um grupo social. Os costumes, valores, hábitos, as práticas sociais, as experiências interferem em suas ações e nos significados que atribuem às pessoas, às coisas e às relações".

Discutir sobre infâncias, educação infantil e cidade neste estudo nos fez constatar que por meio das diferentes linguagens (oral, contação de história, audiovisual e artes visuais), as crianças representam a cidade das mais diversas formas, como o lugar onde as pessoas moram, trabalham, estudam, passeiam, convivem e brincam, tudo isso, em companhia de seus pares e de outras categorias geracionais. Além disso, ao discorrerem sobre os lugares que frequentam na cidade, elas reivindicam melhorias para os espaços públicos, sobretudo para os parques e praças, sendo estes, pontos que podem ser convidativos para a coabitação e o encontro.

Isso demonstra que é preciso que elas sejam ouvidas, que tenham o direito de se posicionar e de expressar suas opiniões, pois, a nosso ver, em todo o tempo, elas contam sobre a sua cidade. De acordo com Müller (2012), a premência de que as crianças sejam incluídas nas discussões sobre a cidade em que habitam representam um modo de inseri-las nos processos de mudança, dado que captar seus pontos de vista é relevante para se propor um novo modelo de cidade, o que as permitirá serem reconhecidas como cidadãs, possibilitando-as adquirir novos conhecimentos na, para e com a cidade. Trata-se de pensarmos a construção de um espaço público compartilhado de convivência plural entre os diferentes sujeitos, isto é, uma cidade que inclua as crianças e suas infâncias.

Esperamos que os resultados da pesquisa possam colocar em evidência fronteiras pouco conhecidas entre a cidade, as instituições de educação infantil e suas infâncias. Esta é uma forma de problematizar a escola, considerada como o modelo de uma adequada presença da criança na cidade, colocando em cena a cidade como instância de mediação societária, um suporte indispensável à equalização das oportunidades e medida de reconhecimento público e igual dignidade às crianças e suas infâncias. Tornam-se importantes estudos futuros que melhor analisem como as vivências das crianças na, para e com a cidade podem inspirar o desenvolvimento de práticas pedagógicas nas instituições de educação infantil, considerando práticas mais democráticas de ação, tendo as crianças, suas infâncias e as instituições de educação infantil como questões mobilizadoras para se pensar as possibilidades educativas da cidade e consolidar formas de reciprocidades públicas entre a educação formal, nãoformal e informal; os acontecimentos da cidade e as demandas das crianças pequenas como sujeitos de direitos.

\section{Referências}

Algebaile, M. A. P. (1996). Entrelaçando vozes infantis: uma pesquisa feita na escola pública. In: Kramer, S., \& Leite, M. I. (Orgs.). Infância: fios e desafios da pesquisa, 115-135. Papirus.

Araújo, V. C. de (1996). Mistificação da infância: imagem do passado no presente. In: Araújo, V. C. de. (Org.). Criança: do reino da necessidade ao reino da liberdade, 45-74. Edufes.

Araújo, V. C. de (2011). A cidade como espaço público de educação e de afirmação da cidadania: a experiência de Vitória/ES, Brasil. Revista Brasileira de Política e Administração da Educação, 27 (1), 135-148. https://seer.ufrgs.br/rbpae/article/view/19973/11604. https://doi.org/10.21573/vol27n12011.19973. 
Araújo, V. C. de, Siller, R. R., Soares, L. P. R. G., Vieira, V. G., Silva, E. M., \& Ramos, I. O. (2008). Os sentidos atribuídos pelas crianças à cidade. Revista

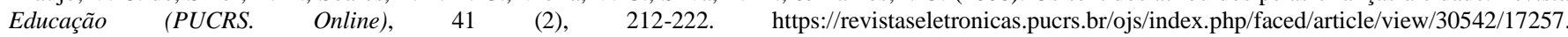
https://doi.org/10.15448/1981-2582.2018.2.30542.

Araújo, V. C. de (2019). Quando as crianças nos ensinam sobre a cidade. Educar em revista, 35 (75), 319-334. https://revistas.ufpr.br/educar/article/view/65510/39112. 10.1590/0104-4060.65510.

Barros, M. de (2015). Meu quintal é maior do que o mundo. Rio de Janeiro: Objetiva.

Borba, A. M. (2007). O brincar como um modo de ser e estar no mundo. In: Beauchamp, J.; Pagel, S. D.; Nascimento, A. R. (Orgs.). Ensino Fundamental de nove anos: Orientações para a inclusão da criança de seis anos de idade, 33-44. MEC/SEB.

Cenpec. (2006). Carta das Cidades $\quad$ Educadoras. Cadernos $\quad$ Cenpec $\quad$ Nova $\quad$ série, $1 \quad$ (1), $156 \quad$ - 161 http://cadernos.cenpec.org.br/cadernos/index.php/cadernos/article/view/165/194. http://dx.doi.org/10.18676/cadernoscenpec.v1i1.165.

Chisté, P. de S., \& Sgarbi, A. D. (2015). Cidade educativa: reflexões sobre educação, cidadania, escola e formação humana. Revista Debates em Educação Científica e Tecnológica, 5 (4), 84 - 114. https://ojs.ifes.edu.br/index.php/dect/article/view/134. https://doi.org/10.36524/dect.v5i04.134.

Debortoli, J. A. O. (2008). Imagens contraditórias da infância: crianças e adultos na construção de uma cultura pública coletiva. In: Debortoli, J. A. O, Martins, M. F. A., \& Martins, S. (Orgs.). Infâncias na metrópole, 71-86. UFMG.

Dias, M. S., \& Ferreira, B. R. Espaços públicos e infâncias urbanas: a construção de uma cidadania contemporânea. Revista Brasileira de Estudos Urbanos e Regionais, 17(3), 118-133, https://rbeur.anpur.org.br/rbeur/article/view/5150. https://doi.org/10.22296/2317-1529.2015v17n3p118.

Fernandes, N. (2009). Infância, direitos e participação: Representações, práticas e poderes. Edições Afrontamento.

Freire, P. (1993). Educação permanente e as cidades educativas. Vila das Letras.

Gadotti, M. (2006). A escola na cidade que educa. Cadernos Cenpec | Nova série, 133-139. http://cadernos.cenpec.org.br/cadernos/index.php/cadernos/article/view/160/189. https://doi.org/10.18676/cadernoscenpec.v1i1.160.

Gil, A. C. (2002). Como elaborar projetos de pesquisa. Atlas.

Gobbi, M. A. (2009). Desenho infantil e oralidade: instrumentos para pesquisas com crianças pequenas. In: Faria, A. L. G. de, Demartini, Z. de B. F., \& Prado, P. D. (Orgs.). Por uma cultura da infância: metodologias de pesquisa com crianças, 69-93. Autores Associados.

Gobbi, M. A. (2014). Mundos na ponta do lápis: desenhos das crianças pequenas ou de como estranhar o familiar quando o assunto é criação infantil. Linhas críticas, 20 (41), 147-165. https://periodicos.unb.br/index.php/linhascriticas/article/view/4265. https://doi.org/10.26512/lc.v20i41.4265.

Gomes, A. M. R., \& Gouvea, M. C. S. de. (2008). A criança e a cidade: entre a sedução e o perigo. In: Debortoli, J. A. O.; Martins, M. de F. A., \& Martins, S. (Orgs.). Infâncias na metrópole, 45 - 67. Editora UFMG.

Kramer, S. (2007). A infância e sua singularidade. In: Beauchamp, J., Pagel, S. D., \& Nascimento, A. R. (Orgs.). Ensino Fundamental de nove anos: orientações para a inclusão da criança de seis anos de idade, 13-24. MEC/SEB.

Lansky, S., Gouvea, M. C. S. de, \& Gomes, A. M. R. (2014). Cartografia das infâncias em região de fronteira em Belo Horizonte. Educação e Sociedade, 35 (128), 717-740. https://www.scielo.br/j/es/a/qpQynMG5PkH7mK8sXkDdqqN/abstract/?lang=pt. https://doi.org/10.1590/ES0101-73302014128647.

Lei n. 9.394, de 20 de dezembro de 1996. Estabelece as diretrizes e bases da educação nacional. http://portal.mec.gov.br/seed/arquivos/pdf/tvescola/leis/lein9394.pdf.

Lei n. 13.005, de 25 de junho de 2014. Aprova o Plano Nacional de Educação - PNE e dá outras providências. http://www.planalto.gov.br/ccivil_03/_ato2011-2014/2014/lei/113005.htm.

Lopes, J. J. M. (2018). Geografia e educação infantil. Porto Alegre: Mediação.

Loureiro, A. S. de S. (2010). A cidade também é nossa: Jardim de Infância, espaço urbano e educação para a cidadania. (Dissertação de mestrado). Universidade do Minho, Braga, VRM, Portugal.

Marconi, M. A., \& Lakatos, E. M. (2003). Técnicas de pesquisa: planejamento e execução de pesquisas, amostragens e técnicas de pesquisas, elaboração, análise e interpretação de dados. Atlas.

Müller, F., \& Redin, M. M. (2007). Sobre as crianças, a infância e as práticas escolares. In: Redin, E., Redin, M. M., \& Müller, F. (Orgs.). Infâncias: cidades e escolas amigas das crianças, 11-22. Mediação.

Müller, F. (2012). Infância e Cidade: Porto Alegre através das lentes das crianças. Educação e Realidade, 37 (1), 295-318. https://seer.ufrgs.br/educacaoerealidade/article/view/16161/16049. 10.1590/2175-623616161.

Pinto, M., \& Sarmento, M. J. (1997). As crianças e a infância: definindo conceitos, delimitando campo. In: Sarmento, M. J., \& Pinto, M. (Orgs.). As crianças: contextos e identidades, 1-9. Braga: Centro de Estudos da Criança, Universidade do Minho.

Resolução n. 2, de 22 de dezembro de 2017. Institui e orienta a implantação da Base Nacional Comum Curricular, a ser respeitada obrigatoriamente ao longo das etapas e respectivas modalidades no âmbito da Educação Básica. http://portal.mec.gov.br/index.php?option=com_docman\&view=download\&alias=79631rcp002-17-pdf\&category_slug=dezembro-2017-pdf\&Itemid=30192.

Resolução n. 5, de 17 de dezembro de 2009. Fixa as diretrizes curriculares nacionais para a educação infantil. Recuperado em 19 março, 2021, de http://www.crmariocovas.sp.gov.br/downloads/ccs/concurso_2013/pdfs/resol_federal_5_09.pdf. 
Research, Society and Development, v. 10, n. 7, e19510716544, 2021

(CC BY 4.0) | ISSN 2525-3409 | DOI: http://dx.doi.org/10.33448/rsd-v10i7.16544

Rocha, E. A. C. (2008). Por que ouvir as crianças? Algumas questões para um debate científico multidisciplinar. In: CRUZ, S. H. V. (Org.). A criança fala: a escuta de crianças em pesquisas, 43-51. Cortez.

Sarmento, M. J., \& Soares, N. F.; Tomás, C. A. (2007). Políticas Públicas e Participação Infantil. Revista Educação, Sociedade e Cultura, 1 (25), 183 - 206. http://repositorium.sdum.uminho.pt/handle/1822/36753.

Sarmento, M. J. (2007). Visibilidade social e estudo da infância. In: Vasconcelos, V. M. \& Sarmento, M. J. (Orgs.). Infância (In) visível, 25-49. Araraquara: Junqueria e Marin.

Silva, J. P., Barbosa, S. N. F., \& Kramer, S. (2005). Questões Teórico-metodológicas da Pesquisa com crianças. Revista Perspectiva, 23 (01), $41-64$. https://periodicos.ufsc.br/index.php/perspectiva/article/view/9694/8905. https://doi.org/10.5007/\%25x.

Unicef. (2009). Situação mundial da infância 2009 (edição especial): celebrando 20 anos da Convenção sobre os Direitos da Criança. http://www.unicef.org/brazil/sowc20anosCDC/cap1-dest15.html. 